\title{
Animal Models of Chemical Carcinogenesis: Driving Breakthroughs in Cancer Research for 100 Years
}

\author{
Christopher J. Kemp ${ }^{1}$ \\ Division of Human Biology, Fred Hutchinson Cancer Research Center, Seattle, Washington 98109
}

\begin{abstract}
The identification of carcinogens in the workplace, diet, and environment through chemical carcinogenesis studies in animals has directly contributed to a reduction of cancer burden in the human population. Reduced exposure to these carcinogens through lifestyle changes, government regulation, or change in industry practices has reduced cancer incidence in exposed populations. In addition to providing the first experimental evidence for cancer's relationship to chemical and radiation exposure, animal models of environmentally induced cancer have and will continue to provide important insight into the causes, mechanisms, and conceptual frameworks of cancer. More recently, combining chemical carcinogens with genetically engineered mouse models has emerged as an invaluable approach to study the complex interaction between genotype and environment that contributes to cancer development. In the future, animal models of environmentally induced cancer are likely to provide insight into areas such as the epigenetic basis of cancer, genetic modifiers of cancer susceptibility, the systems biology of cancer, inflammation and cancer, and cancer prevention.
\end{abstract}

Any model is by definition an imperfect representation of that which it seeks to emulate. Regardless of how accurate any given cancer model is, its true value should be measured by its ability to guide research and, from a practical perspective, to protect human health. Mouse, rat, and other animal models of chemically induced cancer have been remarkably faithful in revealing underlying mechanisms of carcinogenesis and pinpointing both genetic and environmental factors that influence cancer susceptibility in the human population.

There are currently two major applications of animal models of chemical carcinogenesis. One is experimental and translational cancer research, where the objectives are to learn about the causes and mechanisms of cancer, as well as chemoprevention or early detection of cancer. The second, more practical application is to test chemicals with potential human exposure for carcinogenic activity in the so-called carcinogen bioassay. We focus here on mouse models of chemical and radiation carcinogenesis, with an emphasis on combining such models with genetically engineered mouse models (GEMMs). Highlights of selected chemical carcinogenogenesis models, including history, applications, protocols, and future directions, will be discussed. A brief description of the history and use of the carcinogen bioassay will also be presented.

\footnotetext{
${ }^{1}$ Correspondence: cjkemp@fhcrc.org

(c) 2015 Cold Spring Harbor Laboratory Press

Cite this introduction as Cold Spring Harb Protoc; doi:10.1101/pdb.top069906
} 
It is widely accepted that cancer is a "genetic disease" (Vogelstein and Kinzler 2004). Much support for this concept has come from the detection of mutated genes in tumors and the use of GEMMs that are designed to carry mutations in the orthologous genes that are mutated in human cancers. These mouse models, to varying degrees of accuracy, recapitulate the pathogenesis of human cancer and provide important experimental evidence for the genetic basis of cancer (Van Dyke and Jacks 2002; Becher and Holland 2006; Frese and Tuveson 2007). Current estimates, however, indicate that inherited genetic predisposition makes a relatively minor contribution to most cancers (Lichtenstein et al. 2000), implying that most cancer-related mutations are somatically acquired through spontaneous events or as a result of environmental exposure. Human cancer has a prominent and, in some cases, overwhelming environmental etiology, indicating that cancer is also an "environmental disease" (Doll and Peto 1981; IARC 1990). Environment is defined as anything people interact with, including exposure from lifestyle choices, natural and medical radiation, sunlight, workplace exposure, drugs, and substances in the air, water, and soil (OTA 1981; IOM 2001). Thus, although GEMMs mirror some of the genetic, biologic, and pathologic features of human cancer, they do not by themselves take into account the complexity of environmental exposures that contribute to cancer. Combining chemical and other environmental exposures with genetically defined mouse models provides a useful experimental setting in which to study the interaction between host genotype and environmental exposures that ultimately dictate cancer risk.

\section{¿ EARLY STUDIES AND THE USE OF ANIMALS TO IDENTIFY CARCINOGENS}

More than 200 years ago, the first report linking environmental exposure and cancer was published by the English physician and surgeon Percivall Pott (Pott 1775). Dr. Pott noted that patients with scrotal skin cancer commonly reported employment as chimney sweeps in their youth. These young workers were chronically exposed to high levels of soot and tar and developed cancer after a long latency. The observation of tumor latency noted by Pott was highly prescient and predated the concept of multistage cancer. Over 100 years later, in 1895, Rehn reported observations of increased bladder cancers in workers exposed to aniline dyes (Rehn 1895). These and other seminal epidemiologic observations ultimately gave rise to the field of chemical carcinogenesis (Lawley 1994). It was not until 1915, with a paper first published in English in 1918, that a direct causal link between chemical exposure and cancer was established. Yamagiwa and Ichikawa (1918) reported that chronic application of coal tar to rabbit ears gave rise initially to benign lesions, some of which eventually developed into malignant epidermal tumors. This research was soon followed by similar studies in mice (Tsutsui 1918). In the 1930s, the first pure chemical compounds, such as polycyclic aromatic hydrocarbons (PAHs) benzo[a]pyrene, dibenz[a,h]anthracene, and 3-methylcholanthrene, were shown to induce tumors in mice, firmly establishing defined chemical entities as a cause of cancer (Cook et al. 1932; Kennaway 1955). PAHs consist of multiple fused benzene rings and are formed during incomplete combustion of organic matter. PAHs are a major component of cigarette smoke and air pollution particulates and, to this day, are widely distributed in the environment and found in certain foods. In part because of the widespread distribution of PAHs such as benzo[a]pyrene, there are few epidemiologic studies linking its exposure to human cancer, and animal models provide the main evidence of their carcinogenicity.

Following the reports of bladder cancer in workers in the dye industry, Sasaki and Yoshida (1935) succeeded in inducing liver cancer in rats after feeding them the azo dye $o$-amidoazotoluene. In 1936, Kinosita reported that 4-dimethyl-aminoazobenzene induced liver cancer (Kinosita 1936), and in 1941, bladder cancer and other cancers were found in rats exposed to 2-acetylaminofluorine (Weisberger and Weisburger 1958). Studies of azo dyes also provided the first evidence that some chemicals require metabolic activation by the host to cause cancer (Miller and Miller 1947). The 
epidemiology of aromatic amines and cancer is largely the epidemiology of industry-related bladder cancer, and due in no small part to these early animal studies, the exposure of workers to these compounds has been greatly reduced. Aromatic amines are still used in industry during chemical synthesis and are found in cigarette smoke. The link between cigarette smoking and bladder cancer has been attributed to aromatic amines (Vineis and Pirastu 1997), indicating an ongoing threat from these compounds.

As additional animal studies were performed, evidence of links between cancer and environmental exposure to carcinogens continued to emerge. Between 1950 and 1975, ethyl carbamate (urethane) was used as a sedative, and large numbers of Japanese patients were exposed to this carcinogen. Urethane was shown to induce lung cancer in mice as early as 1943 (Nettleship et al. 1943), but decades passed before its deliberate use was stopped (Miller 1991). Urethane is found at low levels in many foods as a by-product of fermentation. Like many other carcinogens, urethane requires metabolic activation by the p450 system, in this case to vinyl carbamate epoxide, which can covalently bind to DNA to form mutagenic DNA adducts (Forkert 2010). The $N$-nitroso compounds represent another important class of chemical carcinogens. One of these, $N$-nitrosodimethylamine (DMN), was first shown to be carcinogenic in rats (Magee and Barnes 1956). Subsequently, many additional $N$ nitroso compounds were shown to cause cancer in animals, and nearly every species tested is susceptible to cancer induced by DMN or the related $N$-nitrosodiethylamine (DEN) (Magee and Barnes 1967). Nitrosamines are present in the environment and produced during digestion and may contribute broadly to cancer (Miller and Miller 1979). Other early animal studies establishing a causal link between environmental exposures and cancer include UV-radiation-induced skin cancer (Findlay 1928) and X-ray-induced lymphomas, ovarian cancer, and other tumors in mice (Furth and Furth 1936). Collectively, these landmark studies through the early to mid-20th century established unequivocal causal connections between chemical or radiation exposure and the subsequent development of cancer (Boyland 1969). Importantly, these studies contributed directly to a reduction in human exposure to many of these agents and a subsequent reduction in cancer risk through a variety of mechanisms, including lifestyle changes, government regulation, and alternative industry practices.

\section{THE CARCINOGEN BIOASSAY: MICE AND RATS AS THE UNSUNG HEROES} IN CHEMICAL SAFETY ASSESSMENT

Evidence of chemical carcinogenesis in animal models and epidemiologic studies, combined with the burgeoning development of the chemical industry and the resultant widespread environmental contamination and exposures, led directly to the initiation of animal testing programs by the National Cancer Institute (NCI) in the 1970s to identify potential carcinogens and to establish safe levels of exposure. The NCI Carcinogenesis Bioassay Program operated until formation of the National Toxicology Program (NTP), whose mission is to coordinate federal toxicology programs and to refine toxicology and carcinogenicity tests (National Toxicology Program 2011). Chemicals that are selected for study are subjected to a 2-yr bioassay involving both sexes of two species, usually inbred and outbred strains of mice or rats, and exposure at several predetermined doses (Fung et al. 1995). In addition, the NTP employs GEMMs on a case-by-case basis in short-term, more hypothesis-based cancer bioassays (Pritchard et al. 2003). Laboratory tests in animals are a major source of the evidence that is used to set regulatory standards for potential human exposure. This research is summarized in the Handbook of Carcinogenic Potency and Genotoxicity Databases (Gold and Zeiger 1997), which includes data from over 5000 experiments and 1298 chemical agents in over 1000 papers and 400 technical reports from the NCI/NTP.

Attesting to the value of carcinogen testing in animals, some 30 substances first shown to cause cancer in animals were subsequently linked to human cancer through epidemiologic studies; these substances include estrogen, formaldehyde, diethylstilbestrol, dichlorodiphenyltrichloroethane (DDT), vinyl chloride, 2,3,7,8-TCDD, radon gas, beryllium, asbestos, 4-aminobiphenyl, bis(chloro- 
C.J. Kemp

methyl)ether, and 1,3 butadiene (Huff 1993; Rall 2000). Viewed another way, $\sim 25 \%$ of the substances that are causally or strongly associated with human cancer were first identified as carcinogens in animals.

Accumulated evidence from the rodent bioassay permits some generalizations when comparing human with rodent cancer susceptibility. Cancer rates are low in humans and high in rodents in the liver (excepting hepatitis $\mathrm{C}$-associated liver cancer), kidney, forestomach, and thyroid gland. Cancer rates are high in both species in the lung, mammary gland, the hematopoietic system, bladder, oral cavity, and skin. Cancer rates are high in humans and low in rodents in prostate gland, pancreas, colon/rectum, and cervix/uterus.

Extrapolating data from the rodent carcinogen bioassay to acceptable levels of human exposure involves consideration of the weight of evidence, mechanisms of action, threshold levels, and doseresponse patterns of the test compounds. As part of this process, it is useful to classify chemical carcinogens into two broad categories: genotoxic and nongenotoxic. These categories may be further divided into eight subclasses: direct-acting carcinogens, procarcinogens, solid-state carcinogens, hormones, immunosuppressors, co-carcinogens, and promoters (Weisburger and Williams 1981). Much work remains to determine the mechanism of action for many of these compounds and to establish safe levels of exposure.

Collectively, the findings from the NCI/NTP bioassays have been used by federal and state regulatory agencies to reduce exposure to mutagenic carcinogens. Another outcome of these studies was the development and use of the Ames test and other short-term genotoxic assays widely used by regulatory agencies to screen chemicals before human exposure.

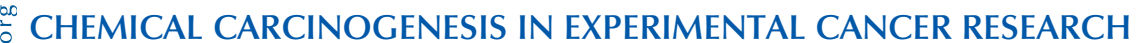

In addition to their role in identifying potential human carcinogens, chemical and radiation carcinogenesis studies have made seminal contributions to many cornerstone principles of experimental oncology, many predating the molecular biology era (Pitot 1983). For example, it was noted that many chemicals did not cause cancer at the site of exposure but were often active at distal sites, often in the liver. In 1947, the Millers noticed aromatic amine liver carcinogens bound to liver proteins (Miller and Miller 1947) and speculated that binding to such macromolecules was important for the carcinogenicity of these compounds. Following up on early skin tumor painting studies, Heidelberger showed that PAHs bound to the DNA of mouse skin, and Lawley established a correlation between carcinogenicity and DNA binding, implicating DNA as the relevant target (Brookes and Lawley 1964; Goshman and Heidelberger 1967). Because chemical carcinogens were covalently bound to DNA, these and other findings led to two important concepts: that many carcinogens are inactive in their native form and require metabolic activation to become active and carcinogenic, and that mutation of DNA may be a key event in their mechanism of action as carcinogens.

Berenblum and Shubik applied 7,12-dimethylbenz[a] anthracene (DMBA) and croton oil in sequence to induce skin tumors in mice and from their analysis concluded that carcinogenesis occurs through at least two discrete stages: initiation, an irreversible event mediated in this case by DMBA, and promotion, a reversible process involving chronic exposure to an irritant such as croton oil (Berenblum and Shubik 1947). The phorbol ester 12-O-tetradecanoylphorbol-13-acetate (TPA) was later shown to be the active ingredient in croton oil (Verma and Boutwell 1980). The stages of carcinogenesis were subsequently expanded to include malignant progression, a process in which benign neoplasms convert to malignant, invasive lesions, sometimes with metastatic dissemination. It is now generally accepted that cancer arises as a multistep process, an idea that can be traced back to the writings of Dr. Pott (Pott 1775).

After the finding of carcinogens bound to DNA and the correlation between DNA binding and carcinogenicity (Brookes and Lawley 1964), it was not until the discovery of mutated oncogenes and tumor suppressor genes in both human tumors and chemically induced rodent tumors (Balmain and Pragnell 1983; Zarbl et al. 1985; Brown et al. 1990; Burns et al. 1991) that the link initially 
discovered in 1915 between environmental exposures to carcinogens, mutations, and cancer was completed. Collectively, these findings helped to solidify the concepts of mutagens as carcinogens and the genetic basis of cancer. When viewed through the lens of Nowell's clonal evolution model of cancer development (Nowell 1976), it is easy to see the major impact of these concepts, even if unstated, on the design and interpretation of many oncology experiments even to this day. The study of chemical carcinogenesis models has contributed to any other fundamental concepts in cancer biology and genetics, and many of the first carcinogens to be identified are still widely used as experimental agents.

\section{COMBINING CHEMICAL CARCINOGENESIS AND GENETICALLY ENGINEERED MODELS OF CANCER}

Over the past two decades, GEMMs have been increasingly used to model cancer. These models are the subject of numerous articles and recent reviews (Van Dyke and Jacks 2002; Becher and Holland 2006; Frese and Tuveson 2007). Given that cancer is the product of complex interplay between environmental exposure and genetic susceptibility, the combined use of chemical carcinogenesis and genetically engineered models is a logical approach to unraveling these interactions. The combined effect of genetics with chemical exposure can easily be seen in the increased spectrum of tumors observed in some GEMMs after exposure to carcinogens or radiation. The tumor suppressor p53 provides one early illustrative example. p53 knockout mice were originally reported to be susceptible to spontaneous lymphomas and sarcomas but not epithelial tumors (Donehower et al. 1992; Jacks et al. 1994). This observation was curious, because p53 is frequently mutated in both human and mouse epithelial tumors. To address this conundrum, p53-deficient mice were subjected to the DMBA/TPA multistage skin tumor protocol. Interestingly, p53-deficient mice did not develop more skin tumors, but those tumors that did develop progressed much more rapidly to malignant, invasive, and metastatic carcinomas (Kemp et al. 1993). This pointed to a role for p53 in suppressing malignant progression, a conclusion that has been borne out in a number of subsequent studies (Jackson et al. 2005; Lewis et al. 2005). Thus, p53 plays a stage-specific role in epithelial cancer, and chemical exposure was required to reveal this phenotype. Because Ras mutations were found in skin tumors from both wild-type and p53-deficient mice, these experiments also illustrated cooperation between mutations in Ras and p53 during malignant progression.

p53-deficient mice are also susceptible to DMN-induced hemangiosarcomas (Harvey et al. 1993), ionizing radiation-induced lymphomas and sarcomas (Kemp et al. 1994), and UV-induced skin cancer (Ziegler et al. 1994; Jiang et al. 1999), and are sensitive to other chemicals and agents (Tennant et al. 1999). The susceptibility of mice deficient in Arf, a tumor suppressor that regulates p53, to DMBA/TPA-induced skin cancer progression (Kelly-Spratt et al. 2004), chemically induced hemangiosarcomas (Busch et al. 2012), and lung cancer (Busch et al. 2013) (see Protocol: Induction of Lung Tumors in Mice with Urethane [Gurley et al. 2014a]) collectively highlight the Arf/p53 signaling axis as an important barrier to chemical- and radiation-induced cancer.

Another notable example illustrating the value of combining chemical and radiation carcinogenesis with GEMMs involved the cyclin-dependent kinase inhibitor p27 (CDKN1B). While its role as a CDK inhibitor made p27 a candidate tumor suppressor, the initial paucity of mutations in CDKN1B in tumors cast doubts on its importance in human cancer (Philipp-Staheli et al. 2001). Further, p27 knockout mice displayed only modest susceptibility to spontaneous tumor formation, which was restricted to the pituitary gland (Fero et al. 1996; Kiyokawa et al. 1996). These findings were difficult to reconcile with the clear association of low levels of p27 protein expression with poor prognosis in breast, lung, prostate, colon, and other cancers (Chu et al. 2008). This puzzle was at least partially solved when $\mathrm{p} 27$-deficient mice were challenged with chemical carcinogens or ionizing radiation. Following exposure, both $p 27$ null and heterozygous mice showed a marked susceptibility to cancer relative to wild-type littermates in a wide range of tissues, including the lung, small intestine, colon, prostate, and hematopoietic tissue (Fero et al. 1998; Di Cristofano et al. 2001; Philipp-Staheli et al. 
C.J. Kemp

2002; Kelly-Spratt et al. 2009). In addition to establishing a causal and pan-tissue role for p27 in tumor suppression, analysis of tumors from $p 27^{+/-}$mice showed no mutation or loss of heterozygosity in the remaining wild-type $C d k n 1 b$ allele, providing clear evidence of tumor suppressor gene haploinsufficiency. Simultaneously, Donehower reported that p53 also showed evidence of haploinsufficient tumor suppression (Venkatachalam et al. 1998). Before these landmark experiments, tumor suppressor genes were widely, if not universally, thought to function in a genetically recessive manner, requiring mutational hits on both alleles before cancers could develop. In contrast, these studies showed that loss of just a single allele was sufficient. Haploinsufficiency has now been described for many tumor-suppressor genes (Payne and Kemp 2005; Scuoppo et al. 2012) and may be the rule rather than the exception. Thus, combining chemical carcinogenesis and GEMMs was instrumental in modifying one of the central dogmas of cancer genetics. As a postscript, recent data from cancer genome sequencing projects have found that $C D K N 1 B$ is one of the most significantly mutated genes in human breast cancer (Ellis et al. 2012), underscoring the predictive value of mouse models to identify tumor suppressor genes.

An important lesson from these and numerous other examples is that the spontaneous tumor spectra of GEMMs only tell part of the story, and appropriate environmental or dietary exposures should be routinely considered in the phenotypic analysis of GEMMs. The different spectra of tumors observed between mice and humans has been attributed to inherent differences between the species and has been used to argue against the value of mice as a model of human cancer (Anisimov et al. 2005). At least some of these differences, however, are almost certainly due to very different environmental exposures between laboratory mice and humans. Another potentially confounding difference when comparing mouse to human cancer susceptibility is that mouse model experiments are frequently performed on one or two inbred strain backgrounds, whereas the human population is genetically diverse. It is well established that genetic background affects cancer risk in both humans and mice (Balmain 2002; Dragani 2003).

Inbred strains differ widely in their susceptibility to spontaneous or chemically induced neoplasia in most if not all tissues, including the lung, liver (Drinkwater and Ginsler 1986; Dragani et al. 1995a), skin, and colon (Demant 2003). In most cases, treatment with tissue-specific chemical carcinogens to induce tumors is an essential strategy for the discovery, mapping, and eventual identification of genetic modifiers of cancer risk. For example, topical application of the carcinogen DMBA was used to develop the highly susceptible SENCAR mouse strain (Slaga 1986) and to map and characterize multiple skin cancer susceptibility loci (Skts) using both inbred strains and interspecies Mus musculus $\times$ Mus spretus crosses (Nagase et al. 1995; Angel and DiGiovanni 1999; Quigley et al. 2009). Urethane or $N$-ethyl- $N$-nitrosourea (ENU) treatment of $\mathrm{A} / \mathrm{J}$ and other strains of mice was used to identify lung cancer susceptibility loci, including the Pas, Par, and Sluc alleles (Lynch 1926; Dragani et al. 1995b; Tripodis et al. 2001; Liu et al. 2006). Treatment of inbred strains with DEN, ENU, or urethane to induce liver tumors revealed dramatic differences in susceptibility to hepatocarcinogenesis, leading to the identification of $\mathrm{Hcs}$ and $\mathrm{Hcr}$ modifier alleles (Drinkwater and Ginsler 1986; Dragani et al. 1995a; Poole et al. 1996). The carcinogens 1,2-dimethylhydrazine (DMH) and azoxymethane $(\mathrm{AOM})$ as well as the germline-susceptible strain $\mathrm{Apc}^{\mathrm{Min}}$ were used to identify small intestine and colon cancer susceptibility alleles Mom and Scc (Dietrich et al. 1993; van Wezel et al. 1999; Bissahoyo et al. 2005). Going forward, in-depth analysis of these genetic modifiers will provide insight into gene $\times$ gene or epistatic interactions that predict cancer risk, novel mechanisms in cancer progression, and, by extrapolation, human cancer susceptibility.

In addition to revealing mechanisms of genotype $\times$ environment interaction and identifying genes that modulate environmentally induced cancer, the enhanced susceptibility of some GEMMs to 
chemical agents is valuable to regulatory agencies. For example, transgenic Ras and p53 heterozygous knockout mice are routinely used by the NTP in the carcinogen bioassay, thus reducing time, saving money, and allowing increased throughput to test additional potential human carcinogens (Tennant et al. 1996, 1999; Ashby 2001). Because of the broad susceptibility of p27-deficient mice to epithelial cancer, it has been argued that p27-deficient mice would also be useful for the carcinogen bioassay (Payne and Kemp 2003).

\section{COMMON MODELS OF CHEMICAL CARCINOGENESIS}

Probably the most extensively researched animal model of cancer is the multistage chemical carcinogenesis model of mouse skin (see Abel et al. [2009] for detailed protocols). In addition to having an unbroken experimental history that goes back for the better part of a century, this model has a number of experimental advantages, including simplicity, the ability to observe and quantify the number and growth rate of tumors, the ability to study initiation, promotion, progression, and metastasis in sequence, and the ability to study the genes associated with these stages. One of the more useful attributes of the DMBA/TPA skin cancer protocol is that the induced tumors harbor mutations in the oncogene Ras and the tumor suppressor p53 with remarkable consistency. Since Quintanilla and Balmain discovered mutations in Hras in chemically induced skin tumors 30 years ago (Balmain and Pragnell 1983; Quintanilla et al. 1986), studies in many laboratories have confirmed that DMBA/TPAinduced tumors almost uniformly contain the identical $\mathrm{A}>\mathrm{T}$ mutation in codon 61 of Hras. This remarkable consistency lends itself to the progressive accumulation of knowledge about genetic, biologic, and environmental modifiers of oncogenic Ras (Kemp 2005). Dozens, if not hundreds, of different inbred mouse strains and GEMMs have been subjected to the DMBA/TPA protocol, providing a rich repository of knowledge on the genetics and biology of multistage cancer. Virtually any general feature of cancer biology can be or has been explored with this model, including inflammation, angiogenesis, epigenetics, and chemoprevention, to name just a few. Recent examples include dissection of the role of Arf, p53, and EMT in metastasis (Ruddell et al. 2008; Tsai et al. 2012) and the tracing of cell lineage to determine the clonal origin of cancer (Driessens et al. 2012).

Table 1 highlights selected examples of tissue-specific (liver, lung, breast, colon) or pan-tissue models of chemical carcinogenesis that have been widely used in regulatory settings and experimental cancer research. Further details are provided in Protocol: Induction of Lung Tumors in Mice with Urethane (Gurley et al. 2014a), Protocol: Induction of Liver Tumors in Mice with N-Ethyl- $N$-Nitrosourea or N-Nitrosodiethylamine (Gurley et al. 2014b), and Protocol: Induction of Colon Cancer in Mice with 1,2-Dimethylhydrazine (Gurley et al. 2014c).

In summary, the ease of applying chemical carcinogens to any strain background or GEMM facilitates the study of gene $\times$ gene and gene $\times$ environment interactions and is valuable for revealing

TABLE 1. Common models of chemical carcinogenesis

\begin{tabular}{lll}
\hline Tissue & Agent & Route \\
\hline Pan tissue & lonizing radiation & Whole-body exposure \\
Skin & ENU & i.p. injection \\
& DMBA & Topical application \\
& B [a]P & Topical application \\
Liver & UV & Topical exposure \\
& DEN & i.p. injection \\
Lung & ENU & i.p. injection \\
& Phenobarbital & Drinking water \\
Breast & Urethane & i.p. injection \\
Colon & NNK & i.p. injection \\
\hline
\end{tabular}

ENU, $N$-ethyl- $N$-nitrosourea; DMBA, 7,12-dimethylbenz[a] anthracene; DEN, $N$-nitrosodiethylamine; NNK, nicotine-derived nitrosamine ketone; AOM, azoxymethane; DMH, 1-2-dimethylhydrazine; i.p., intraperitoneal. 
C.J. Kemp

latent tumor predisposition of GEMMs. The versatility and widespread use of animal models of chemical carcinogenesis, which began in the middle part of the last century, engenders progressive accumulation of insight into the genetics and biology of cancer.

\section{THE FUTURE OF CHEMICAL CARCINOGENESIS}

Animal models of chemical carcinogenesis have made a major contribution toward establishing the precept that the most effective way to prevent cancer is to reduce exposure to mutagenic carcinogens. However, many important chemicals and agents that are carcinogenic are not obviously mutagenic, including hormones, phenobarbital, asbestos, some metals, and chlorinated hydrocarbons such as DDT and polychlorinated biphenyls (PCBs). Application of these agents to selected GEMMs that carry mutations in genes that influence the response to these agents may help unravel additional mechanisms of carcinogenesis. It can reasonably be anticipated that some of these mechanisms will involve epigenetic events. Abundant epidemiologic and molecular data point to epigenetic mechanisms as an important component in the link between early environmental exposure and later risk of diseases such as cancer (Jirtle and Skinner 2007); examples of carcinogens that induce epigenetic changes include nickel, arsenic, and diethylstilbestrol (Anderson 2004; Herceg 2007). Novel approaches that combine environmental exposures with GEMMs are needed to determine both the environmental causes of epigenetic alterations and the mechanistic role of these alterations in cancer development. Clonal analysis of cancer has confirmed that tumors are genetically and phenotypically heterogeneous (Driessens et al. 2012; Greaves and Maley 2012). This heterogeneity likely contributes to treatment failure, and modeling this heterogeneity in mice is a significant challenge. Because models of chemical carcinogenesis recapitulate important aspects of the etiology of human cancer, and chemically induced tumors are often highly heterogeneous, these models may serve as a useful venue to study tumor heterogeneity and the implications for tumor response to therapy. Animal models of cancer that combine both genetic and environmental elements will continue to play a critical role in the quest to reduce the burden of cancer on the human population.

\section{ACKNOWLEDGMENTS}

The author thanks Norman Drinkwater, Jef French, and Russell Moser for helpful comments on the manuscript. Work in the author's laboratory is funded by grants from the National Cancer Institute Mouse Models of Human Cancer Consortium (U01 CA141550), the National Institute of Environmental Health Science (R01 ES020116), and the Department of Defence (CA093616).

\section{REFERENCES}

Abel EL, Angel JM, Kiguchi K, DiGiovanni J. 2009. Multi-stage chemical carcinogenesis in mouse skin: Fundamentals and applications. Nat Protoc 4: 1350-1362.

Anderson LM. 2004. Introduction and overview. Perinatal carcinogenesis: Growing a node for epidemiology, risk management, and animal studies. Toxicol Appl Pharmacol 199: 85-90.

Angel JM, DiGiovanni J. 1999. Genetics of skin tumor promotion. Prog Exp Tumor Res 35: 143-157.

Anisimov VN, Ukraintseva SV, Yashin AI. 2005. Cancer in rodents: Does it tell us about cancer in humans? Nat Rev Cancer 5: 807-819.

Ashby J. 2001. Expectations for transgenic rodent cancer bioassay models. Toxicol Pathol 29: 177-182.

Balmain A. 2002. Cancer as a complex genetic trait: Tumor susceptibility in humans and mouse models. Cell 108: 145-152.

Balmain A, Pragnell IB. 1983. Mouse skin carcinomas induced in vivo by chemical carcinogens have a transforming Harvey-ras oncogene. Nature 303: 72-74.
Becher OJ, Holland EC. 2006. Genetically engineered models have advantages over xenografts for preclinical studies. Cancer Res 66: 3355-3358, discussion.

Berenblum I, Shubik P. 1947. A new, quantitative, approach to the study of the stages of chemical carcinogenesis in the mouse's skin. Br J Cancer 1: 383-391.

Bissahoyo A, Pearsall RS, Hanlon K, Amann V, Hicks D, Godfrey VL, Threadgill DW. 2005. Azoxymethane is a genetic background-dependent colorectal tumor initiator and promoter in mice: Effects of dose, route, and diet. Toxicol Sci 88: 340-345.

Boyland F. 1969. The correlation of experimental carcinogenesis and cancer in man. Prog Exp Tumor Res 11: 222-234.

Brookes P, Lawley PD. 1964. Evidence for the binding of polynuclear aromatic hydrocarbons to the nucleic acids of mouse skin: Relation between carcinogenic power of hydrocarbons and their binding to deoxynucleic acid. Nature 202: 781-784. 
Brown K, Buchmann A, Balmain A. 1990. Carcinogen-induced mutations in the mouse c-Ha-ras gene provide evidence of multiple pathways for tumour progression. Proc Natl Acad Sci 87: 538-542.

Burns PA, Kemp CJ, Gannon JV, Lane DP, Bremner R, Balmain A 1991. Loss of heterozygosity and mutational alterations of the p53 gene in skin tumors of interspecific hybrid mice. Oncogene 6: 2363 2369.

Busch SE, Gurley KE, Moser RD, Kemp CJ. 2012. ARF suppresses hepatic vascular neoplasia in a carcinogen-exposed murine model. $J$ Pathol 227: 298-305.

Busch SE, Gurley KE, Moser R, Kelly-Spratt KS, Liggitt D, Kemp CJ. 2013. p1 $9^{\text {arf }}$ inhibits the growth and malignant progression of carcinogen induced non small cell lung cancer. Oncogene (in press).

Chu IM, Hengst L, Slingerland JM. 2008. The Cdk inhibitor p27 in human cancer: Prognostic potential and relevance to anticancer therapy. Nat Rev Cancer 8: 253-267.

Cook JW, Hieger I, Kennaway EL, Mayneord WV. 1932. The production of cancer by pure hydrocarbons. $R$ Soc Proc 111: 455-484.

Demant P. 2003. Cancer susceptibility in the mouse: Genetics, biology and implications for human cancer. Nat Rev Genet 4: 721-734.

Di Cristofano A, De Acetis M, Koff A, Cordon-Cardo C, Pandolfi PP. 2001. Pten and p27KIP1 cooperate in prostate cancer tumor suppression in the mouse. Nat Genet 27: 222-224.

Dietrich WF, Lander ES, Smith JS, Moser AR, Gould KA, Luongo C, Borenstein N, Dove W. 1993. Genetic identification of Mom-1, a major modifier locus affecting Min-induced intestinal neoplasia in the mouse. Cell 75: 631-639.

Doll R, Peto R. 1981. The causes of cancer: Quantitative estimates of avoidable risks of cancer in the United States today. J Natl Cancer Inst 66 1191-1308.

Donehower LA, Harvey M, Slagle BL, McArthur MJ, Montgomery CA Jr, Butel JS, Bradley A. 1992. Mice deficient for p53 are developmentally normal but susceptible to spontaneous tumours. Nature 356: 215-221.

Dragani TA. 2003. 10 years of mouse cancer modifier loci: Human relevance. Cancer Res 63: 3011-3018.

Dragani TA, Manenti G, Gariboldi M, De Gregorio L, Pierotti MA. 1995a. Genetics of liver tumor susceptibility in mice. Toxicol Lett 82: 613-619.

Dragani TA, Manenti G, Pierotti MA. 1995b. Genetics of murine lung tumors. Adv Cancer Res 67: 83-112.

Driessens G, Beck B, Caauwe A, Simons BD, Blanpain C. 2012. Defining the mode of tumour growth by clonal analysis. Nature 488: 527-530.

Drinkwater NR, Ginsler JJ. 1986. Genetic control of hepatocarcinogenesis in C57BL/6J and C3H/HeJ inbred mice. Carcinogenesis 7: 1701-1707.

Ellis MJ, Ding L, Shen D, Luo J, Suman VJ, Wallis JW, Van Tine BA, Hoog J, Goiffon RJ, Goldstein TC, et al. 2012. Whole-genome analysis informs breast cancer response to aromatase inhibition. Nature 486: 353-360.

Fero ML, Rivkin M, Tasch M, Porter P, Carow CE, Firpo E, Polyak K, Tsai LH, Broudy V, Perlmutter RM, et al. 1996. A syndrome of multiorgan hyperplasia with features of gigantism, tumorigenesis, and female sterility in p27-deficient mice. Cell 85: 733-744.

Fero ML, Randel E, Gurley KE, Roberts JM, Kemp CJ. 1998. The murine gene p27Kip1 is haplo-insufficient for tumour suppression. Nature 396: $177-180$.

Findlay GM. 1928. Ultra-violet light and skin cancer. The Lancet ii: 10701073.

Forkert PG. 2010. Mechanisms of lung tumorigenesis by ethyl carbamate and vinyl carbamate. Drug Metab Rev 42: 355-378.

Frese KK, Tuveson DA. 2007. Maximizing mouse cancer models. Nat Rev Cancer 7: 645-658.

Fung VA, Barrett JC, Huff J. 1995. The carcinogenesis bioassay in perspective: Application in identifying human cancer hazards. Environ Health Perspect 103: 680-683.

Furth J, Furth OB. 1936. Neoplastic diseases produced in mice by general irradiation with X-rays. Am J Cancer 28: 54-65.

Gold LS, Zeiger E. 1997. Handbook of carcinogenic potency and genotoxicity databases. CRC Press, Boca Raton, FL.

Goshman LM, Heidelberger C. 1967. Binding of tritium-labeled polycyclic hydrocarbons to DNA of mouse skin. Cancer Res 27: 1678-1688.

Greaves M, Maley CC. 2012. Clonal evolution in cancer. Nature 481: 306313.

Gurley KE, Moser RD, Kemp CJ. 2014a. Induction of lung tumors in mice with urethane. Cold Spring Harb Protoc doi: 10.1101/pdb.prot077446.
Gurley KE, Moser RD, Kemp CJ. 2014b. Induction of liver tumors in mice with $\mathrm{N}$-ethyl- $\mathrm{N}$-nitrosourea or $\mathrm{N}$-nitrosodiethylamine. Cold Spring Harb Protoc doi: 10.1101/pdb.prot077438.

Gurley KE, Moser RD, Kemp CJ. 2014c. Induction of colon cancer in mice with 1,2-dimethylhydrazine. Cold Spring Harb Protoc doi: 10.1101/pdb. prot077453.

Harvey M, McArthur MJ, Montgomery CA Jr, Butel JS, Bradley A, Donehower LA. 1993. Spontaneous and carcinogen-induced tumorigenesis in p53-deficient mice. Nat Genet 5: 225-229.

Herceg Z. 2007. Epigenetics and cancer: Towards an evaluation of the impact of environmental and dietary factors. Mutagenesis 22: 91-103.

Huff J. 1993. Chemicals and cancer in humans: First evidence in experimental animals. Environ Health Perspect 100: 201-210.

IARC (International Agency for Research on Cancer). Scientific Publication No. 100. (ed. Tomatis L). Who Press, New York. 1990. Cancer: Causes, occurrence, and control.

IOM (Institute of Medicine). 2001. Rebuiliding the unity of health and the environment: A new vision of environmental health for the 21st century workshop summary (ed. Institute of Medicine). National Academy of Sciences, Washington, DC.

Jacks T, Remington L, Williams BO, Schmitt EM, Halachmi S, Bronson RT, Weinberg RA. 1994. Tumor spectrum analysis in p53-mutant mice. Curr Biol 4: 1-7.

Jackson EL, Olive KP, Tuveson DA, Bronson R, Crowley D, Brown M, Jacks T. 2005. The differential effects of mutant p53 alleles on advanced murine lung cancer. Cancer Res 65: 10280-10288.

Jiang W, Ananthaswamy HN, Muller HK, Kripke ML. 1999. p53 protects against skin cancer induction by UV-B radiation. Oncogene 18: 42474253.

Jirtle RL, Skinner MK. 2007. Environmental epigenomics and disease susceptibility. Nat Rev Genet 8: 253-262.

Kelly-Spratt KS, Gurley KE, Yasui Y, Kemp CJ. 2004. p19Arf suppresses growth, progression, and metastasis of Hras-driven carcinomas through p53-dependent and -independent pathways. PLoS Biol 2: $1138-1149$.

Kelly-Spratt KS, Philipp-Staheli J, Gurley KE, Hoon-Kim K, Knoblaugh S, Kemp CJ. 2009. Inhibition of PI-3K restores nuclear p27 $7^{\text {Kip } 1}$ expression in a mouse model of Kras-driven lung cancer. Oncogene 38: 3652-3662.

Kemp CJ. 2005. Multistep skin cancer in mice as a model to study the evolvability of cancer cells. Sem Cancer Biol 15: 460-473.

Kemp CJ, Wheldon T, Balmain A. 1994. p53 deficient mice are extremely susceptible to radiation-induced tumorigenesis. Nat Genet 8: 66-69.

Kemp CJ, Donchower LA, Bradley A, Balmain A. 1993. Reduction of p53 gene dosage does not increase initiation or promotion but greatly enhances malignant progression of chemically induced skin tumors. Cell 74: 813-822.

Kennaway EL. 1955. The identification of a carcinogenic compound in coal tar. Br Med J ii: 749-752.

Kinosita R. 1936. Researches on the carcinogenesis of the various chemical substances. Gann 30: 423-426.

Kiyokawa H, Kineman RD, Manova-Todorova KO, Soares VC, Hoffman ES, Ono M, Khanam D, Hayday AC, Frohman LA, Koff A. 1996. Enhanced growth of mice lacking the cyclin-dependent kinase inhibitor function of p27(Kip1). Cell 85: 721-732.

Lawley PD. 1994. Historical origins of current concepts of carcinogenesis. Adv Cancer Res 65: 17-111.

Lewis BC, Klimstra DS, Socci ND, Xu S, Koutcher JA, Varmus HE. 2005. The absence of p53 promotes metastasis in a novel somatic mouse model for hepatocellular carcinoma. Mol Cell Biol 25: 1228-1237.

Lichtenstein P, Holm NV, Verkasalo PK, Iliadou A, Kaprio J, Koskenvuo M, Pukkala E, Skytthe A, Hemminki K. 2000. Environmental and heritable factors in the causation of cancer-Analyses of cohorts of twins from Sweden, Denmark, and Finland. N Engl J Med 343: 78-85.

Liu P, Wang Y, Vikis H, Maciag A, Wang D, Lu Y, Liu Y, You M. 2006. Candidate lung tumor susceptibility genes identified through wholegenome association analyses in inbred mice. Nat Genet 38: 888-895.

Lynch CJ. 1926. Studies on the relation between tumor susceptibility and heredity. III. Spontaneous tumors of the lung in mice. J Exp Med 43: 339-355.

Magee PN, Barnes JM. 1956. The production of malignant primary hepatic tumours in the rat by feeding dimethylnitrosamine. Br JCancer 10: 114122. 


\section{C.J. Kemp}

Magee PN, Barnes JM. 1967. Carcinogenic nitroso compounds. Adv Cancer Res 10: 163-246.

Miller JA. 1991. The need for epidemiological studies of the medical exposures of Japanese patients to the carcinogenic ethyl carbamate (urethane) from 1950 to 1975. Jpn J Cancer Res 82: 1323-1324.

Miller JA, Miller EC. 1947. The metabolism and carcinogenicity of $p$-dimethylaminoazobenzene and related compounds in the rat. Cancer Res 7: 39-41.

Miller EC, Miller JA. 1979. Milestones in chemical carcinogenesis. Semin Oncol 6: 445-460.

Nagase H, Bryson S, Cordell H, Kemp CJ, Fee F, Balmain A. 1995. Distinct genetic loci control development of benign and malignant skin tumours in mice. Nature Genet 10: 424-429.

National Toxicology Program. 2011. 12th Report on Carcinogens. U.S. Department of Health and Human Services Public Health Service National Toxicoloy Program.

Nettleship A, Henshaw PS, Meyer HL. 1943. Induction of pulmonary tumors in mice with ethyl carbamate (urethane). J Natl Cancer Inst 4: 309-319.

Nowell PC. 1976. The clonal evolution of tumor cell populations. Science 194: 23-28.

OTA (Office of Technology Assessment). 1981. Assessment of technologies for determining cancer risks from the environment (ed. Office of Technology Assessment). U.S. Government Printing Office, Washington, DC.

Payne SR, Kemp CJ. 2003. p2 $7^{\text {Kip1 }}(C d k n 1 b)$-deficient mice are susceptible to chemical carcinogenesis and may be a useful model for carcinogen screening. Toxicol Pathol 31: 355-363.

Payne SR, Kemp CJ. 2005. Tumor suppressor genetics. Carcinogenesis 26: 2031-2045.

Philipp-Staheli J, Payne SR, Kemp CJ. 2001. p27(Kip1): Regulation and function of a haploinsufficient tumor suppressor and its misregulation in cancer. Exp Cell Res 264: 148-168.

Philipp-Staheli J, Kim KH, Payne SR, Gurley KE, Liggitt D, Longton G, Kemp CJ. 2002. Pathway-specific tumor suppression. Reduction of p27 accelerates gastrointestinal tumorigenesis in Apc mutant mice, but not in Smad3 mutant mice. Cancer Cell 1: 355-368.

Pitot HC. 1983. Contributions to our understanding of the natural history of neoplastic development in lower animals to the cause and control of human cancer. Cancer Surveys 2: 519-538.

Poole TM, Chiaverotti TA, Carabeo RA, Drinkwater NR. 1996. Genetic analysis of multistage hepatocarcinogenesis. Prog Clin Biol Res 395: 33-45.

Pott P. 1775. Chirugical observations relative to the cataract, the polypus of the nose, the cancer of the scrotum, the different kinds of ruptures and the mortifications of the toes and feet. Hawkes, Clarke, and Collins, London.

Pritchard JB, French JE, Davis BJ, Haseman JK. 2003. The role of transgenic mouse models in carcinogen identification. Environ Health Perspect 111: $444-454$

Quigley DA, To MD, Perez-Losada J, Pelorosso FG, Mao JH, Nagase H, Ginzinger DG, Balmain A. 2009. Genetic architecture of mouse skin inflammation and tumour susceptibility. Nature 458: 505-508.

Quintanilla M, Brown K, Ramsden M, Balmain A. 1986. Carcinogen-specific mutation and amplification of Ha-ras during mouse skin carcinogenesis. Nature 322: 78-80.

Rall DP. 2000. Laboratory animal tests and human cancer. Drug Metab Rev 32: $119-128$.
Rehn L. 1895. Uberblasentumoren bei fuchsinarbeiten. Arch Klin Chir 50: 588 .

Ruddell A, Kelly-Spratt KS, Furuya M, Parghi SS, Kemp CJ. 2008. p19/Arf and $\mathrm{p} 53$ suppress sentinel lymph node lymphangiogenesis and carcinoma metastasis. Oncogene 27: 3145-3155.

Sasaki T, Yoshida T. 1935. Liver carcinoma induced by feeding $O$-amidoazotoluene. Arch Pathol Anat 295: 175-220.

Scuoppo C, Miething C, Lindqvist L, Reyes J, Ruse C, Appelmann I, Yoon S, Krasnitz A, Teruya-Feldstein J, Pappin D, et al. 2012. A tumour suppressor network relying on the polyamine-hypusine axis. Nature 487: 244-248.

Slaga TJ. 1986. SENCAR mouse skin tumorigenesis model versus other strains and stocks of mice. Environ Health Perspect 68: 27-32.

Tennant RW, Spalding J, French JE. 1996. Evaluation of transgenic mouse bioassays for identifying carcinogens and noncarcinogens. Mutat Res 365: 119-127.

Tennant RW, Stasiewicz S, Mennear J, French JE, Spalding JW. 1999. Genetically altered mouse models for identifying carcinogens. IARC Sci Publ 123-150.

Tripodis N, Hart AA, Fijneman RJ, Demant P. 2001. Complexity of lung cancer modifiers: Mapping of thirty genes and twenty-five interactions in half of the mouse genome. J Natl Cancer Inst 93: 1484-1491.

Tsai JH, Donaher JL, Murphy DA, Chau S, Yang J. 2012. Spatiotemporal regulation of epithelial-mesenchymal transition is essential for squamous cell carcinoma metastasis. Cancer Cell 22: 725-736.

Tsutsui H. 1918. Uber das kustlich erzeugte cancroid bei der maus. Gann 12: $17-21$

Van Dyke T, Jacks T. 2002. Cancer modeling in the modern era: Progress and challenges. Cell 108: 135-144.

van Wezel T, Ruivenkamp CA, Stassen AP, Moen CJ, Demant P. 1999. Four new colon cancer susceptibility loci, Scc6 to Scc9 in the mouse. Cancer Res 59: 4216-4218.

Venkatachalam S, Shi YP, Jones SN, Vogel H, Bradley A, Pinkel D, Donehower LA. 1998. Retention of wild-type 53 in tumors from p53 heterozygous mice: Reduction of p53 dosage can promote cancer formation. EMBO J 17: 4657-4667.

Verma AK, Boutwell RK. 1980. Effects of dose and duration of treatment with the tumour promoting agent, 12-O-tetradecanoylphorbol-13acetate. Carcinogenesis 1: 271-276.

Vineis P, Pirastu R. 1997. Aromatic amines and cancer. Cancer Causes Control 8: 346-355.

Vogelstein B, Kinzler KW. 2004. Cancer genes and the pathways they control. Nat Med 10: 789-799.

Weisberger EK, Weisburger JH. 1958. Chemistry, carcinogenicity, and metabolism of 2-fluorenamine and related compounds. Adv Cancer Res 5: $331-431$.

Weisburger JH, Williams GM. 1981. Carcinogen testing: Current problems and new approaches. Science 214: 401-407.

Yamagiwa K, Ichikawa K. 1918. Experimental study of the pathogenesis of carcinoma. J Cancer Res 3: 1-29.

Zarbl H, Sukumar S, Arthur AV, Martin-Zanca D, Barbacid M. 1985. Direct mutagenesis of Ha-ras- 1 oncogenes by $N$-nitroso- $N$-methylurea during initiation of mammary carcinogenesis in rats. Nature 315: 382-385.

Ziegler A, Jonason AS, Leffell DJ, Simon JA, Sharma HW, Kimmelman J, Jacks T, Brash DE. 1994. Sunburn and p53 in the onset of skin cancer. Nature 372: 773-776. 


\section{Animal Models of Chemical Carcinogenesis: Driving Breakthroughs in Cancer Research for 100 Years}

Christopher J. Kemp

Cold Spring Harb Protoc; doi: 10.1101/pdb.top069906

\begin{tabular}{cc}
$\begin{array}{r}\text { Email Alerting } \\
\text { Service }\end{array}$ & Receive free email alerts when new articles cite this article - click here. \\
\hline $\begin{array}{c}\text { Subject } \\
\text { Categories }\end{array}$ & $\begin{array}{c}\text { Browse articles on similar topics from Cold Spring Harbor Protocols. } \\
\text { Mouse (437 articles) }\end{array}$ \\
\hline
\end{tabular}

